
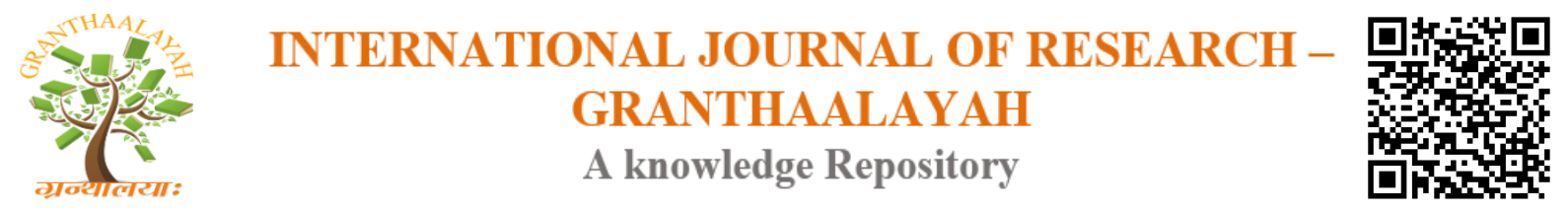

Social

\title{
CONTRIBUTION OF EMOTIONAL INTELLIGENCE IN OUR EDUCATION SYSTEM
}

\author{
K.Vijayalakshmi ${ }^{* 1}$ \\ ${ }^{*}$ Ph.D. Scholar (Part Time), Department of Education, Dravidian University, Kuppam, India
}

\begin{abstract}
Emotional Intelligence (EI) also known as Emotional Quotient (EQ) is one of the hot topics among Teachers and learners. Emotional Intelligence (EI) has had a huge impact on management since Daniel Goleman (1995) published his book popular book on EI for a wider audience. From fairly humble beginnings. EI has come into its own as one of the most popular psychological concepts of the last decade. EI has been used by some as an umbrella term that comprises elements such as 'soft skills', 'people skills', and a general ability to cope with life's demands.
\end{abstract}

Keywords: Contribution; Education System; Intelligence.

Cite This Article: K.Vijayalakshmi. (2017). "CONTRIBUTION OF EMOTIONAL INTELLIGENCE IN OUR EDUCATION SYSTEM.” International Journal of Research Granthaalayah, 5(12), 121-127. https://doi.org/10.29121/granthaalayah.v5.i12.2017.480.

\section{Introduction}

In other words 'Emotional intelligence gives you a competitive edge'. It has been argued around the world that having great intellectual abilities may make you a superb fiscal analyst or legal scholar, but a highly developed emotional intelligence will make you a candidate for CEO or a brilliant trial lawyer" (Goleman, 1997, p. 76). To some people the term 'Emotional Intelligence' is an oxymoron. As we know intelligence implies rational thinking, supposedly without any emotion. The key to this compelling question touches many areas of research in Psychology and Education, the two fields which rely heavily on the various facts of EI in demystifying some key questions. In this article, I strive to look for understanding categories of EI in its various dimensions, contribution of EI in balanced life, essential role of EI in balanced life, various ways to take control Emotions and its affect health and carrier.

\section{Categories of Emotional Intelligence}

The emotional intelligence has the following categories in our education system. 


\subsection{Self-Awareness}

The ability to recognize an emotion as it "happens" is the key to your EQ. Developing selfawareness requires tuning into your true feelings. If you evaluate your emotions, you can manage them. The major elements of self-awareness are:

- Emotional awareness- Your ability to recognize your own emotions and their effects.

- Self-confidence- Sureness about your self-worth and capabilities.

\subsection{Self-Regulation}

You often have little control over when you experience emotions. You can, however, have some say in how long an emotion will last by using a number of techniques to alleviate negative emotions such as anger, anxiety or depression. A few of these techniques include recasting a situation in a more positive light, taking a long walk and meditation or prayer. Self-regulation involves

- Self-control- Managing disruptive impulses.

- Trustworthiness- Maintaining standards of honesty and integrity.

- Conscientiousness- Taking responsibility for your own performance.

- Adaptability- Handling change with flexibility.

- Innovation- Being open to new ideas.

\subsection{Motivation}

To motivate yourself for any achievement requires clear goals and a positive attitude. Although you may have a predisposition to either a positive or a negative attitude, you can with effort and practice learn to think more positively. If you catch negative thoughts as they occur, you can reframe them in more positive terms - which will help you achieve your goals. Motivation is made up of:

- Achievement drive- Your constant striving to improve or to meet a standard of excellence.

- Commitment- Aligning with the goals of the group or organization.

- Initiative- Readying yourself to act on opportunities.

- Optimism- Pursuing goals persistently despite obstacles and setbacks.

\subsection{Empathy}

The ability to recognize how people feel is important to success in your life and career. The more skillful you are at discerning the feeling behind others' signals the better you can control the signals you send them. An empathetic person excels at:

- Service orientation- Anticipating, recognizing and meeting clients' needs.

- Developing others- Sensing what others need to progress and bolstering their abilities.

- Leveraging diversity- Cultivating opportunities through diverse people.

- Political awareness- Reading a group's emotional currents and power relationships.

- Understanding others- Discerning the feelings behind the needs and wants of others. 


\subsection{Social Skills}

The development of good interpersonal skills is tantamount to success in your life and career. In today's always-connected world, everyone has immediate access to technical knowledge. Thus, "people skills" are even more important now because you must possess a high EQ to better understand, empathize and negotiate with others in a global economy. Among the most useful skills are:

- Influence- Wielding effective persuasion tactics.

- Communication- Sending clear messages.

- Leadership- Inspiring and guiding groups and people.

- Change catalyst- Initiating or managing change.

- Conflict management- Understanding, negotiating and resolving disagreements.

- Building bonds- Nurturing instrumental relationships.

- Collaboration and cooperation- Working with others toward shared goals.

- Team capabilities- Creating group synergy in pursuing collective goals.

What factors are at play when people of high IQ fail and those of modest IQ succeed?

How well you do in your life and career is determined by both. IQ alone is not enough; EQ also matters. In fact, psychologists generally agree that among the ingredients for success, IQ counts for roughly $10 \%$ (at best $25 \%$ ); the rest depends on everything else including EQ.

\section{Contribution of Emotional Intelligence in Balanced Life}

EQ reduces procrastination and improves self-confidence. It also allows us to focus on achieving a goal. Not only that, high EQ allows people to delay gratification and strive to achieve longterm goals. High emotional intelligence is also connected with the ability for people to understand what motivates others, build stronger bonds with colleagues in the workplace and relate to them in a positive manner. These characteristics make good candidates for leadership roles in the organisation. A leader is effective when they can recognise the needs of the people reporting to him/her. When their needs are met, people are motivated to perform better. This leads to better workplace satisfaction. A leader can also develop stronger teams by using the emotional diversity of the members to benefit their entire organisation. An organisation that is emotionally intelligent has employees who are productive, motivated and efficient. They are committed to achieving their goals. They're also happy, confident and likable. Team members are able to work together in the most effective manner, and provide better results for the organisation as a whole. As you can see, having high emotional intelligence plays an important role in your career, especially if you're aiming for a leadership position within your organisation. It's important to nurture your EQ, so that you're able to learn, manage and master your emotions, as well as the emotions of others in the workplace. Many experts now believe that a person's emotional intelligence quotient (EQ) may be more important than their IQ and is certainly a better predictor of success, quality of relationships, and overall happiness. 


\section{Essential Process of EI}

If you think emotional intelligence is only important for those who always have to interact or communicate with people, think it again. Emotional intelligence is a gateway to a balanced-life. It's essential to basically every aspect of life.

\subsection{Physical Health}

The ability to take care of our bodies and especially to manage our stress, which has an incredible impact on our overall wellness, is heavily tied to our emotional intelligence. Only by being aware of our emotional state and our reactions to stress in our lives can we hope to manage stress and maintain good health.

\subsection{Mental Well-Being}

Emotional intelligence affects our attitude and outlook on life. It can also help to alleviate anxiety and avoid depression and mood swings. A high level of emotional intelligence directly correlates to a positive attitude and happier outlook on life.

\subsection{Relationships}

By better understanding and managing our emotions, we are better able to communicate our feelings in a more constructive way. We are also better able to understand and relate to those with whom we are in relationships. Understanding the needs, feelings, and responses of those we care about leads to stronger and more fulfilling relationships.

\subsection{Conflict Resolution}

When we can discern people's emotions and empathize with their perspective, it's much easier to resolve conflicts or possibly avoid them before they start. We are also better at negotiation due to the very nature of our ability to understand the needs and desires of others. It's easier to give people what they want if we can perceive what it is.

\subsection{Success}

Higher emotional intelligence helps us to be stronger internal motivators, which can reduce procrastination, increase self-confidence, and improve our ability to focus on a goal. It also allows us to create better networks of support, overcome setbacks, and persevere with a more resilient outlook. Our ability to delay gratification and see the long-term directly affects our ability to succeed.

\subsection{Leadership}

The ability to understand what motivates others, relate in a positive manner, and to build stronger bonds with others in the workplace inevitably makes those with higher emotional intelligence better leaders. An effective leader can recognize what the needs of his people are, so that those 
needs can be met in a way that encourages higher performance and workplace satisfaction. An emotionally savvy and intelligent leader is also able to build stronger teams by strategically utilizing the emotional diversity of their team members to benefit the team as a whole.

Emotional intelligence is still not completely understood, but what we do know is that emotions play a very critical role in the overall quality of our personal and professional lives, more critical even than our actual measure of brain intelligence. While tools and technology can help us to learn and master information, nothing can replace our ability to learn, manage, and master our emotions and the emotions of those around us.

\section{Ways to Take Control the Emotions}

It's never too late to learn anything, so no matter how old you are, you can still take up EI and make the rest of your life better and happier.

\subsection{Observe Your Feelings}

We easily lose touch with our emotions when we're too busy worrying about what to do next and what can be done better. Instead of really taking good care of our emotions, we choose to ignore them most of the time. What we don't realize is that suppressing our emotions only makes things worse. The more we try to put our emotions behind, the more uncontrollable our emotions become.

When we have an emotional reaction to something, it can be due to the fact that we're having some unsolved issues. So next time when you feel like having some negative emotions, calm down and think about why you're experiencing this. Take a deep breath and write down the emotions you're experiencing and the possible reasons.

When you have things written down, you can identify your emotions triggers and think of ways to deal with each of them.

\subsection{Practice Responding, Not Reacting}

Reacting is an unconscious process where we behave in an unconscious way that expresses or relieves an emotion. Responding is a conscious process that involves paying attention to your feelings and deciding how to behave. When you're more aware of your emotional triggers, you can always think about the way to behave in advance.

For example, if you know that you get angry easily and throw temper to colleagues when you're feeling very stressful at work, take note of that and think about what you can do next time when you're experiencing the same trigger. Maybe you can try to tell your colleagues that you need some silent moments because you're feeling stressful at the moment, or maybe you can get a few minutes of alone time just to calm down yourself first. 


\subsection{Stay Humble All the Times}

When you always believe that you're better than others, you'll not see your own faults, and you'll likely to get emotional about things that don't meet your expectation. Try to look at the same thing from a different perspective. Instead of judging someone or something, put yourself in someone else's shoes and try to think or feel like them: would you do or feel the same too and why? In this way, you're likely to understand other people's thoughts and emotions more; and you'll probably learn something new about how to deal with stuff in similar situations too. Be humble enough to know you're not better than anyone, and wise enough to know that you're different from the rest.

\section{Emotional Intelligence to Affect the Career}

EQ affects the everyday decisions employers make, such as promoting, hiring and firing employees. Hiring managers often look at the applicants' emotional intelligence during the hiring process. Those with a higher degree of EQ have a better chance of getting a job offer. The emotional intelligence of current employees is also analysed on a regular basis to determine who amongst them has leadership potential. EQ is often factored into the decision regarding pay raises and promotions. Landing a higher position in the company requires having the right amount of experience, certifications and academic background. However, employers also look at the person's emotional intelligence when looking for a candidate for a management position. EQ helps an individual develop teams who are more productive and happy in their work.

\section{Emotional Intelligence Affects Health}

Experts have connected our EQ with the ability to take care of our body and manage stress. By being aware of our reactions to stress, we can manage stress better and maintain good overall health. EQ also affects your outlook and attitude to life. EQ can help prevent mood swings and depression. A person with a high level of emotional intelligence typically has a happier outlook on life and generally displays a positive attitude all the time. With a better understanding of our emotions, we can communicate our feelings in a more positive manner. We can also understand and relate to our colleagues, which can lead to better working relationships. High EQ also allows a person to discern other people's emotions easier and empathise with their point of view. This is an important characteristic to have when the position requires you to resolve conflicts in the workplace. People with high EQ are also better at negotiating with others, because they're able to understand the desires and needs of individuals right away. It allows them to understand and provide what they want as soon as possible.

\section{Conclusion}

It's never too late to learn anything; it just takes continuous observation and practice. So no matter how old you are, you can still take up EI and make the rest of your life better and happier. So we may conclude that an emotionally intelligent individual is a consistent and dedicated employee; open to everything new, even in the most uncertain prospects and sudden changes. 
Emotionally intelligent individual can keep the strike in the worst circumstances, never surrender and fall into panic but react carefully.

\section{Reference}

[1] Aggarwal, J. C. (2013). Essentials of Educational Psychology, (2nd Edition), Vihas Publishing House Pvt., Ltd., New Delhi.

[2] Bhan, S.P. (2006). Teacher Training. Lotus Press, New Delhi.

[3] Bhatia, H.R. (2002). A Textbook of Educational Psychology (Revised Edition). Macmillan India Limited, New Delhi.

[4] Chauhan,S.S. (2013). Advanced Educational Psychology (7th Edition). Vihas Publishing House Pvt. Ltd. New Delhi.

*Corresponding author.

E-mail address: bharath_edutrust@yahoo.co.in 